\title{
Insights into disseminated MS brain pathology with multimodal diffusion tensor and PET imaging
}

Svetlana Bezukladova, MSc, * Jouni Tuisku, MSc, * Markus Matilainen, MSc, PhD, Anna Vuorimaa, MD, Marjo Nylund, MSc, Sarah Smith, BSc, Marcus Sucksdorff, MD, Mehrbod Mohammadian, MSc, Virva Saunavaara, PhD, Sini Laaksonen, MD, Johanna Rokka, PhD, Juha O. Rinne, MD, PhD, Eero Rissanen, $\mathrm{MD}, \mathrm{PhD}{ }^{*}$ and Laura Airas, $\mathrm{MD}, \mathrm{PhD}^{*}$

Neurol Neuroimmunol Neuroinflamm 2020;7:e691. doi:10.1212/NXI.0000000000000691

\section{Abstract \\ Objective}

To evaluate in vivo the co-occurrence of microglial activation and microstructural white matter (WM) damage in the MS brain and to examine their association with clinical disability.

\section{Methods}

18-kDa translocator protein (TSPO) brain PET imaging was performed for evaluation of microglial activation by using the radioligand $\left[{ }^{11} \mathrm{C}\right](\mathrm{R})-\mathrm{PK} 11195$. TSPO binding was evaluated as the distribution volume ratio (DVR) from dynamic PET images. Diffusion tensor imaging (DTI) and conventional MRI (cMRI) were performed at the same time. Mean fractional anisotropy (FA) and mean (MD), axial, and radial (RD) diffusivities were calculated within the whole normal-appearing WM (NAWM) and segmented NAWM regions appearing normal in cMRI. Fifty-five patients with MS and 15 healthy controls (HCs) were examined.

\section{Results}

Microstructural damage was observed in the NAWM of the MS brain. DTI parameters of patients with MS were significantly altered in the NAWM compared with an age- and sexmatched HC group: mean FA was decreased, and $\mathrm{MD}$ and $\mathrm{RD}$ were increased. These structural abnormalities correlated with increased TSPO binding in the whole NAWM and in the temporal NAWM ( $p<0.05$ for all correlations; $p<0.01$ for RD in the temporal NAWM). Both compromised WM integrity and increased microglial activation in the NAWM correlated significantly with higher clinical disability measured with the Expanded Disability Status Scale score.

\section{Conclusions}

Widespread structural disruption in the NAWM is linked to neuroinflammation, and both phenomena associate with clinical disability. Multimodal PET and DTI allow in vivo evaluation of widespread MS pathology not visible using cMRI.

\author{
Correspondence \\ Dr. Airas \\ laura.airas@utu.fi
}




\section{Glossary}

$\mathbf{A D}=$ axial diffusivity; $\mathbf{B P}_{\mathbf{N D}}=$ binding potential; $\mathbf{c M R I}=$ conventional MRI; DMT $=$ disease-modifying therapy; DTI = diffusion tensor imaging; DVR = distribution volume ratio; EDSS = Expanded Disability Status Scale; FA = fractional anisotropy; $\mathbf{G M}=$ gray matter; $\mathbf{M D}=$ mean diffusivity; $\mathbf{M R}=$ magnetic resonance; $\mathbf{M S S S}=$ MS severity scale; $\mathbf{R D}=$ radial diffusivity; ROI = region of interest; RRMS = relapsing-remitting MS; SPMS = secondary progressive MS; TAC = time-activity curve; $\mathbf{T S P O}=$ translocator protein; $\mathbf{W M}=$ white matter.

Demyelination, inflammation, and neurodegeneration of the brain, spinal cord, and optic nerves are the hallmarks of MS pathogenesis. ${ }^{1}$ Conventional MRI (cMRI) is used for evaluation of focal inflammatory activity and diffuse atrophy for diagnostics and follow-up of MS. ${ }^{2}$ Although cMRI has a wellestablished role in clinical setting and in the evaluation of treatment effect in longitudinal studies with diseasemodifying therapies (DMTs), this imaging modality alone is not able to provide the full picture on MS pathology in vivo. To enhance the detection of diffuse pathologic alterations associated with advanced MS, several methodologies have been applied. With the implementation of diffusion tensor imaging (DTI), it is possible to estimate focal diffusivities and diffusion anisotropy, thereby revealing brain parenchymal alterations at the microstructural level, undetectable in cMRI. ${ }^{3}$ The current understanding is that axial diffusivity $(\mathrm{AD})$ reports on axonal integrity, whereas radial diffusivity $(\mathrm{RD})$ changes associate with myelin integrity. ${ }^{4}$ Decreased fractional anisotropy (FA) has been interpreted to report on a decrease in axonal density, whereas an increase in mean diffusivity (MD) associates with axonal and myelin loss. ${ }^{4}$ In vivo molecular imaging of neuroinflammation using PET with translocator protein (TSPO) binding radioligands provides on the other hand quantifiable molecular data on the activated microglia in the brain. ${ }^{5}$ These advanced imaging methods offer a valuable opportunity to investigate disease pathology in areas of the brain appearing normal in cMRI. They also enable the evaluation of the association of the widespread pathology with clinical MS symptoms. Recently, multiple studies have shown correlations between the increased Expanded Disability Status Scale (EDSS) score and regionally or globally decreased FA and increased MD in MS. ${ }^{6-10}$ Longitudinal DTI revealed that FA increased and $\mathrm{RD}$ decreased after 1-year fingolimod treatment. ${ }^{9}$ Abnormal DTI measures associate also with worse cognitive and functional performance in MS. ${ }^{10-14}$ Similarly, TSPO-PET measurable increased microglial activation in the normalappearing white matter (NAWM) and gray matter (GM) regions is associated with worse clinical disability scores in MS. ${ }^{10,15-17}$ Therefore, the primary objective of this study was to evaluate the diffuse pathology in the NAWM using 3T DTI with simultaneous evaluation of microglial activation using TSPO-PET in a larger cohort of patients with MS. We propose that the combination of these imaging modalities will enable better understanding of the hidden MS pathology not visible using cMRI.

\section{Methods}

\section{Study protocol approval}

The study protocol has been approved by the Ethics Committee of the Hospital District of Southwest Finland. Informed consent was obtained from all participants before entering the study according to the principles of the Declaration of Helsinki.

\section{Participants}

In total, a cohort of 55 patients with MS (40 relapsingremitting MS [RRMS] and 15 secondary progressive MS [SPMS], aged 28-64 years, EDSS score 1-6.5) was examined. Twenty patients with RRMS and 15 patients with SPMS had no immunomodulatory treatment at the time of imaging, whereas other 20 patients with RRMS were using DMTs during imaging (3 patients were taking dimethyl fumarate, 5 patients were on fingolimod treatment, 6 patients had interferon beta 1-a treatment, 4 patients were receiving glatiramer acetate, and 2 were on teriflunomide). All patients with DMT were clinically stable and free from relapses at the time of imaging. Data from 15 healthy controls (HCs) (aged 21-58 years) were included for comparison. The HCs were imaged with $\left[{ }^{11} \mathrm{C}\right](\mathrm{R})-\mathrm{PK} 11195$ and DTI using similar protocols except for 5 participants, from whom only cMRI and DTI data were available. The demographics and clinical characteristics of the study participants are shown in table 1.

Clinical evaluation and neurologic status including the evaluation of disability with the EDSS score and disease severity with the MS severity scale (MSSS) score was performed for all patients with MS.

\section{Data acquisition}

MRI was performed with 3T MRI Phillips Ingenuity (Philips Healthcare, Cleveland, $\mathrm{OH}$ ) scanner by using an 8-channel SENSE head coil. The MRI protocol included T1-, T2weighted, fluid-attenuated inversion recovery, and DTI sequences. For detailed description of the cMRI protocol, see the supplementary material, links.lww.com/NXI/A203.

For DTI sequences, 33 gradient directions were used for imaging of 20 patients with MS (15 SPMS and 5 RRMS), whereas DTI with 64 gradient directions was applied in the rest. All other DTI parameters were equal with $\mathrm{b}$ value $=1,000 \mathrm{~s} / \mathrm{mm}^{-2}$, repetition time/echo time $=9,500 / 120 \mathrm{~ms}$, field-of-view $=256$ $\times 256 \mathrm{~mm}$, spatial resolution $2 \times 2 \times 2 \mathrm{~mm}$, acquisition matrix $128 \times 128 \mathrm{~mm}$, flip angle $=90^{\circ}$, and acceleration factor 2 . 
Table 1 Clinical and conventional MRI parameters of HCs and patients with MS

\begin{tabular}{|c|c|c|c|c|c|c|}
\hline & \multirow[b]{2}{*}{ HCs } & \multirow[b]{2}{*}{ Patients (MS) } & \multirow{2}{*}{$\begin{array}{l}p \text { Value } \\
\text { (HC vs MS) }\end{array}$} & \multicolumn{2}{|l|}{ Disease type } & \multirow{2}{*}{$\begin{array}{l}p \text { Value (RRMS vs } \\
\text { SPMS) }\end{array}$} \\
\hline & & & & RRMS & SPMS & \\
\hline $\mathbf{n}$ & 15 & 55 & - & 40 & 15 & - \\
\hline Sex, M/F & $6 / 9$ & $15 / 40$ & 0.34 & $8 / 32$ & $7 / 8$ & 0.048 \\
\hline Age, median (range) & $\begin{array}{l}45.5 \\
(21.4-58.9)\end{array}$ & $\begin{array}{l}48.0 \\
(30.5-65.7)\end{array}$ & 0.30 & $\begin{array}{l}47.3 \\
(28.4-54.1)\end{array}$ & $\begin{array}{l}54.1 \\
(37.3-64.1)\end{array}$ & 0.080 \\
\hline $\begin{array}{l}\text { Disease duration, } y \text {, mean } \\
\text { (SD) }\end{array}$ & - & $12.7(7.05)$ & - & $11.7(6.73)$ & $15.2(7.50)$ & 0.135 \\
\hline EDSS score, median (range) & - & $3.0(1.0-6.5)$ & - & $2.5(1.0-6.0)$ & $5.0(3.0-6.5)$ & $<0.001$ \\
\hline MSSS score, median (range) & - & $4.1(0.78-8.91)$ & - & $3.9(0.77-6.81)$ & $5.6(2.19-8.91)$ & 0.031 \\
\hline $\begin{array}{l}\text { NAWM volume }\left(\mathrm{cm}^{3}\right) \text {, } \\
\text { mean (SD) }\end{array}$ & $494.0(39.96)$ & $446.0(63.12)$ & 0.003 & $454.8(61.15)$ & $422.6(64.36)$ & 0.092 \\
\hline $\begin{array}{l}\text { GM ctx volume }\left(\mathrm{cm}^{3}\right) \text {, } \\
\text { mean (SD) }\end{array}$ & $496.4(56.26)$ & $433.0(38.63)$ & $<0.001$ & $433.5(38.10)$ & $429.0(41.08)$ & 0.680 \\
\hline $\begin{array}{l}\text { T2 lesion load }\left(\mathrm{cm}^{3}\right) \text {, } \\
\text { mean (range) }\end{array}$ & - & $\begin{array}{l}8.8 \\
(0.48-70.12)\end{array}$ & - & $\begin{array}{l}6.0 \\
(0.48-46.79)\end{array}$ & $\begin{array}{l}19.3 \\
(4.09-70.12)\end{array}$ & 0.002 \\
\hline $\begin{array}{l}\text { T1 lesion load }\left(\mathrm{cm}^{3}\right) \text {, } \\
\text { mean (range) }\end{array}$ & - & $\begin{array}{l}4.7 \\
(0.23-67.89)\end{array}$ & - & $\begin{array}{l}3.5 \\
(0.23-33.53)\end{array}$ & $\begin{array}{l}18.3 \\
(3.7-67.89)\end{array}$ & $<0.0001$ \\
\hline
\end{tabular}

Abbreviations: EDSS = Expanded Disability Status Scale; GM ctx = gray matter cortex; $\mathrm{HC}=$ healthy control; MSSS = MS severity scale; NAWM = normalappearing white matter; RRMS = relapsing-remitting MS; SPMS = secondary progressive MS.

The sex distributions were compared using the $\chi^{2}$ test.

Dynamic 60-minute $\left[{ }^{11} \mathrm{C}\right](\mathrm{R})$-PK11195-PET imaging was performed with the ECAT HRRT scanner (CTI, Siemens Medical Solutions, Knoxville, TN). The radioligand was administered as a smooth, IV bolus injection, the target dose being $500 \mathrm{MBq}$. The mean (SD) of injected activity was 473.6 (59.5) MBq for patients with MS and 498.8 (7.9) $\mathrm{MBq}$ for $\mathrm{HCs}$, with no significant differences between groups.

\section{Data preprocessing and analysis}

The T2 hyperintense lesions were first identified from the fluid-attenuated inversion recovery images using the Lesion Segmentation Toolbox (version 2.0.15). ${ }^{18}$ The T1 image was filled with the manually corrected lesion masks, following a region of interest (ROI) delineation with FreeSurfer 6.0 software. To create an NAWM ROI, cerebellar white matter (WM) and T2 hyperintense lesions were excluded from WM ROI. Next, 6 subregions of NAWM (deep, cingulate, frontal, temporal, occipital, and parietal NAWM) were derived from Freesurfer WM parcellation. ${ }^{19}$ DWI data were preprocessed with ExploreDTI for motion, eddy current, and echo planar imaging/susceptibility-induced distortion correction. ${ }^{20}$ The diffusion tensor estimation method was set to RESTORE (robust estimation of tensors by outlier rejection) approach. ${ }^{21}$ After DTI data preprocessing, 4 maps of interest (FA, MD, $\mathrm{AD}$, and $\mathrm{RD}$ ) were reconstructed from the diffusion tensor map and coregistered in SPM12 (The Wellcome Centre for Human Neuroimaging, University College London) running in MATLAB (MathWorks, Natick, MA) to corresponding
T1-weighted image. Finally, all images were spatially normalized into the MNI152 space.

Because of pooling of DTI data with different number of gradients (33 vs 64), we performed a test whether the number of gradients has an impact on DTI scalar indices. We reduced the number of gradients from 64 to 33, using ExploreDTI function "Shuffle/select $3 \mathrm{D}$ volume(s) in $4 \mathrm{D}^{*}$.nii file(s)" and reevaluated DTI scalars with lower number of gradients for 10 patients. DTI-derived indices for both gradients schemes were comparable (data not shown).

PET images were reconstructed using 17 time frames (total of 3,600 seconds) as described previously. ${ }^{15}$ Thereafter, preprocessing was performed in similar manner as reported earlier. ${ }^{10}$ The dynamic PET images were coregistered to 3D T1 magnetic resonance (MR) images, and then all data were resliced to $1 \mathrm{~mm}$ voxel size. For evaluating $\left[{ }^{11} \mathrm{C}\right](\mathrm{R})$ PK11195 binding, time-activity curves (TACs) from the 7 ROIs were extracted from the preprocessed PET images using the same NAWM masks as in the DTI analyses including the global NAWM and the 6 NAWM subregions.

Regional TSPO radioligand binding was evaluated as distribution volume ratio (DVR) by using a reference region extracted with the supervised cluster algorithm (SuperPK software) as described earlier. ${ }^{15}$ The reference tissue-input Logan method, within 20-60 minutes of time interval, was applied to the regional TACs using the clustered GM reference tissue input. In addition, the modeling was performed at a voxel level, where the 
parametric binding potential $\left(\mathrm{BP}_{\mathrm{ND}}\right)$ maps were calculated using a basis function implementation of simplified reference tissue model ${ }^{22}$ with 250 basis functions. The resulting parametric maps were further transformed to DVR $\left(\mathrm{DVR}=\mathrm{BP}_{\mathrm{ND}}\right.$ +1 ) and normalized into MNI152 space in SPM12.

\section{Statistical methods}

The statistical analyses of DTI, PET imaging, and clinical parameters were performed with $\mathrm{R}$ software (version 3.5.2). The normality distribution of the data was evaluated with the Shapiro-Wilk test. The nonparametric Mann-Whitney $U$ test was chosen for the evaluation of the group differences of nonnormally distributed data and in groups with a low number of participants. The Holm method was used to adjust the $p$ values in case of the multiple comparisons. The Student $t$ test was chosen to test for age difference between groups. PET data were analyzed with analysis of covariance with age as a covariate and with the Tukey honest significance test for the adjustment for the multiple comparisons due to significantly different age between subgroups (mean [SD] age for HC, RRMS, and SPMS: 37.2 (10.9), 45.6 (6.80), and 50.4 (9.23), respectively; $p$ $=0.019$ for SPMS vs HC and $p=0.013$ for RRMS vs HC). The correlational analyses between variables of interest were analyzed with the Spearman nonparametric correlation test, where $p$ values adjusted using the Holm method for the number of ROIs (6) in the brain, separately for each of the DTI parameters or DVR values, and for the EDSS and MSSS scores. Correlational analyses were not adjusted for age, as diffusion parameters and DVR values did not show a significant correlation with age (data not shown).

\section{Voxel-wise image analysis of the MS patient data}

Pearson correlation coefficients were calculated at a voxel level in the NAWM (excluding the lesions) and in the whole WM (including the lesions) between normalized FA and DVR images of 54 patients with MS. One patient was excluded from analysis due to DTI data artefacts. Before the correlation analysis, the parametric images were smoothed with a Gaussian 8-mm full width at half maximum filter to compensate for anatomic variability in image normalization and to improve the signal-to-noise ratio. The resulting $p$ values were corrected for multiple comparisons using the false discovery rate with significance level $p<0.05$.

\section{Data availability}

The raw data used in the preparation of this article can be shared in anonymized format by request of a qualified investigator.

\section{Results}

\section{Increased microglial activation in the NAWM of the MS brain}

Patients with SPMS had higher $\left[{ }^{11} \mathrm{C}\right](\mathrm{R})-\mathrm{PK} 11195$ DVR values as an indication of increased microglial activation in the whole NAWM compared with HCs and with patients with RRMS (1.262 [0.046] vs 1.194 [0.026]; $p=0.0002$ and vs 1.222 [0.039]; $p=0.003$, respectively). Within the NAWM subregions, the $\left[{ }^{11} \mathrm{C}\right](\mathrm{R})-\mathrm{PK} 11195$ DVR was higher in patients with SPMS compared with HCs and with patients with RRMS in frontal NAWM (1.328 [0.081] vs 1.199 [0.033]; $p<0.0001$ and vs 1.245 [0.046]; $p<0.0001$, respectively) and was significantly higher in patients with RRMS compared with HCs; $p=0.048$. $\left[{ }^{11} \mathrm{C}\right]$ (R)-PK11195 DVR was also increased in SPMS vs HC and vs RRMS in cingulate NAWM (1.204 [0.051] vs 1.117 [0.047]; $p=0.0004$ and vs $1.141[0.054] ; p=0.0006$, respectively) and in deep NAWM (1.207 [0.077] vs $1.125[0.034] ; p=0.004$ and vs $1.151[0.058] ; p=0.009$, respectively) (figure 1 ).

\section{Structural WM changes in patients with MS}

In the DTI analyses, we observed a trend for lower mean FA close to statistical significance in the whole NAWM among the patients with MS compared with HCs (mean [SD] 0.341 $[0.026]$ vs $0.356[0.017] ; p=0.064)$. In the diffusivity indices of the whole NAWM, no significant differences were observed.

In the analyses of the segmented subregions of NAWM, FA was significantly decreased in occipital (mean [SD] 0.295 [0.033] vs $0.319[0.018] ; p=0.009)$ and cingulate $(0.452$ [0.050] vs $0.487[0.022] ; p=0.004)$ NAWM, and mean MD and $\mathrm{RD}$ were significantly increased $(0.917$ [0.091] vs 0.847 $[0.047] ; p=0.005$ and $0.667[0.103]$ vs 0.589 [0.045]; $p=0.004$, respectively) in the cingulate NAWM of patients with MS vs HCs. In this and in the next paragraph, mean MD and $\mathrm{RD}$ values are expressed in scientific notation of $10^{-3}$.

When the RRMS, SPMS, and HC subgroups were compared with each other, we observed differences in the whole NAWM, in occipital, and in cingulate WM areas, with more prominent tract damage in the SPMS than in the RRMS subgroup (figure 2). In detail, FA (mean [SD]) was lower in SPMS (0.278 [0.039]) and RRMS (0.302 [0.029]) compared with HC $(0.319[0.018])$ in the occipital NAWM with respective $p$ values of 0.003 and 0.042 . Similarly, FA was lower in SPMS (0.426 [0.071]) and RRMS (0.462 [0.036]) compared with HC $(0.487[0.022])$ in the cingulate NAWM with respective $p$ values of 0.008 and 0.012 . The difference in FA between patients with SPMS and HCs in the whole NAWM still approached statistical significance after correction for multiple comparisons (0.329 [0.034] vs 0.356 [0.017]; $p=0.053$ ). Mean MD was significantly increased in the cingulate NAWM of patients with SPMS and RRMS compared with HCs (0.947 [0.102]; $p=0.006$ and 0.905 [0.085]; $p=0.020$ vs $\mathrm{HC} 0.847$ [0.047], respectively). RD was increased in the cingulate NAWM of both MS subgroups compared with controls (0.651 [0.086]; $p=0.015$ for RRMS and $0.709[0.127] ; p=0.007$ for SPMS vs HC 0.589 [0.045]) and in the occipital NAWM of the SPMS subgroup compared with HCs $(0.722$ [0.098] vs 0.655 [0.030]; $p=0.018)$. 


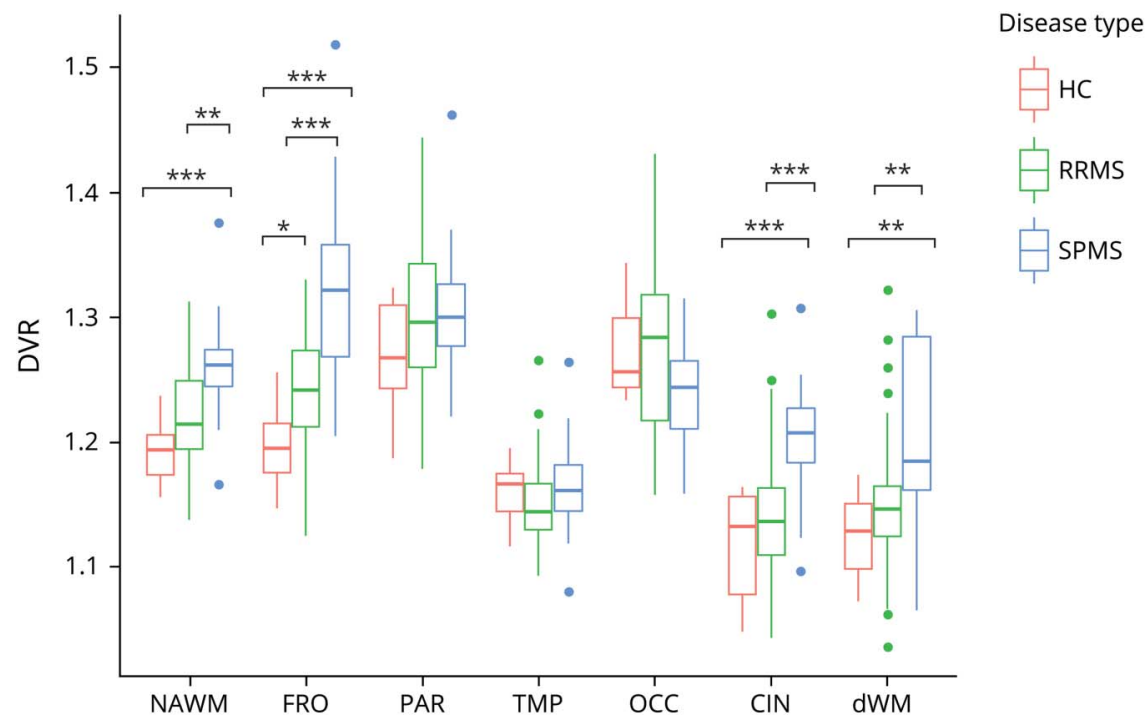

Region of interest-specific binding of $\left[{ }^{11} \mathrm{C}\right](\mathrm{R})$ PK11195 measured as DVR in the global NAWM and in the segmented NAWM of 55 patients with MS compared with $10 \mathrm{HCs}$. Boxplots show median DVR values with the first and third interquartile. Data beyond end of whiskers are outliers and plotted as points. The pairwise comparisons were performed with the analysis of covariance with age as covariate, followed by Tukey post hoc adjustment for multiple comparisons, and were considered statistically significant at the level of $p<0.05$. CIN = cingulate; DVR = distribution volume ratio; $\mathrm{dWM}=$ deep normal-appearing white matter; FRO = frontal; $\mathrm{HC}=$ healthy control; NAWM = normal-appearing white matter; $\mathrm{OCC}=$ occipital; $\mathrm{PAR}=$ parietal; RRMS = relapsing-remitting MS; SPMS = secondary progressive MS; TMP = temporal. ${ }^{*} p<0.05$; $\star_{* *} p<0.01 ; * * * p<0.001$

\section{Decreased tract integrity and increased microglial activation in the NAWM is associated with higher disability in MS}

Several significant correlations between the DTI parameters in the NAWM and disease severity were observed. Decreased mean FA in the NAWM correlated with a higher EDSS score (Spearman correlation $\rho=-0.51, p<0.001$ ), whereas increased diffusivities were also associated with a higher EDSS score $(\rho=0.47, p<0.001$ for $\mathrm{MD} ; \rho=0.30, p=0.031$ for $\mathrm{AD}$; and $\rho=0.51, p<0.001$ for $\mathrm{RD}$ ) (figure 3). In addition, decreased FA correlated with a higher MSSS score ( $\rho=-0.32$; $p=0.018$ ). All diffusivities correlated similarly with the MSSS score: $\rho=0.39, p=0.004$ for $\mathrm{MD} ; \rho=0.34, p=0.013$ for $\mathrm{AD}$; and $\rho=0.38, p=0.005$ for $\mathrm{RD}$. In addition, increased $\left[{ }^{11} \mathrm{C}\right](\mathrm{R})-\mathrm{PK} 11195$ DVR in the NAWM associated with a higher EDSS score (Spearman correlation $\rho=0.37$; $p=0.005$; figure 3 ), but there was no significant correlation between global NAWM TSPO binding and MSSS score $(\rho=0.22 ; p=0.107)$ (table e-1, links.lww.com/NXI/A203).

Within the subregions of the NAWM, both decreased mean FA and increased diffusivity indices as well as increased $\left[{ }^{11} \mathrm{C}\right](\mathrm{R})-\mathrm{PK} 11195$ DVR had several significant correlations with the disability and disease severity scores, the cingulate and occipital NAWM having the strongest associations (table e-1, links.lww.com/NXI/A203).

\section{Increased microglial activation in the NAWM associates with structural WM changes not visible in the cMRI in MS}

The reduced WM tract integrity (demonstrated by reduced FA and increased $\mathrm{MD}, \mathrm{AD}$, and $\mathrm{RD}$ ) was significantly associated with increased $\left[{ }^{11} \mathrm{C}\right](\mathrm{R})-\mathrm{PK} 11195 \mathrm{DVR}$ in the whole $\operatorname{NAWM}(\rho=-0.30, p=0.029$ for FA; $\rho=0.33, p=0.016$ for
$\mathrm{MD} ; \rho=0.28, p=0.039$ for $\mathrm{AD}$; and $\rho=0.34, p=0.013$ for $\mathrm{RD}$; figure 4, A-D).

In addition, associations between increased $\left[{ }^{11} \mathrm{C}\right](\mathrm{R})$ PK11195 DVR and decreased WM integrity were found in some NAWM subregions, most notably in the temporal NAWM $(\rho=-0.39, p=0.02$ for FA; $\rho=0.40, p=0.014$ for $\mathrm{MD} ; \rho=0.37, p=0.036$ for $\mathrm{AD}$; and $\rho=0.43, p=0.007$ for $\mathrm{RD}$ ), table e-2 (links.lww.com/NXI/A203).

\section{Voxel-wise image analysis of PET/DTI data}

The voxel-level correlation analysis showed widespread focal areas of WM, where decreased FA correlated significantly with increased TSPO binding. Significant clusters were found within the superior longitudinal fasciculus, corticospinal tract, cingulate gyrus, corona radiata, and forceps minor, and also within the thalamic radiation. The significant voxel-wise correlation coefficients are illustrated in figure 4E.

\section{Discussion}

This study evaluated structural and molecular brain changes using combined MR and PET in vivo imaging techniques in 55 patients with MS having either RRMS $(n=40)$ or SPMS $(n=15)$. The results from the patients with MS were compared with those from 15 HCs. Altered DTI parameters (decreased FA and increased $\mathrm{MD}, \mathrm{AD}$, and $\mathrm{RD}$ ) in the NAWM and in segmented subregions of the NAWM indicated microstructural damage without visible changes in cMRI, which is in agreement with previously published studies. ${ }^{10-12}$ Microstructural changes were more pronounced in patients with SPMS compared with patients with RRMS, and the most affected area was the cingulate NAWM region, 


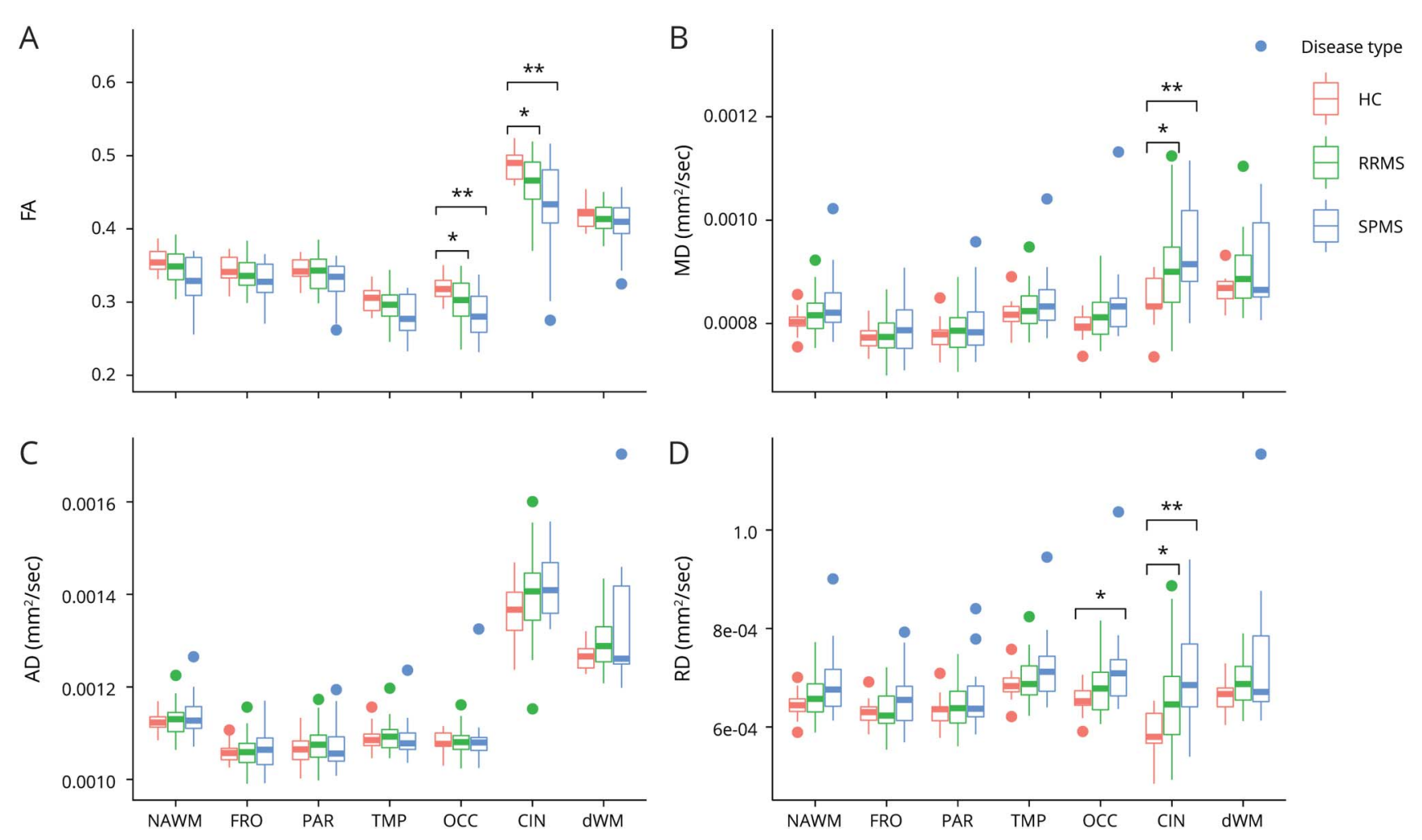

Differences in fractional anisotropy (A), mean diffusivity (B), axial diffusivity (C), and radial diffusivity (D) in the whole and segmented NAWM subregions of patients with MS (RRMS $n=40$, SPMS $n=15)$ and HCS $(n=15)$. Boxplots show median DTI values with the first and third interquartile. Data beyond end of whiskers are outliers and plotted as points. The pairwise comparisons were performed with the Wilcoxon test and were considered statistically significant at the level of $p<0.05$. The Holm method was used to adjust the $p$ values for multiple comparisons. $A D=$ axial diffusivity; $C I N=$ cingulate; $d W M=$ deep normalappearing white matter; $\mathrm{FA}=$ fractional anisotropy; $\mathrm{FRO}=$ frontal; $\mathrm{HC}=$ healthy control; $\mathrm{MD}=$ mean diffusivity; $\mathrm{NAWM}=$ normal-appearing white matter; $\mathrm{OCC}=$ occipital; $\mathrm{PAR}=$ parietal; $\mathrm{RD}=$ radial diffusivity; $\mathrm{RRMS}=$ relapsing-remitting MS; SPMS = secondary progressive MS; TMP = temporal. ${ }^{\star} p<0.05 ; \star \star p<0.01$.

and here, we also saw most significant overlap between changes measured with both PET and DTI. Of interest, higher absolute T2 lesion volume correlated with higher TSPO binding (DVR) in the entire NAWM and in the frontal, parietal, and deep NAWM subregions (supplementary figure e-1, links.lww.com/NXI/A203).

Our multimodal in vivo imaging findings hence contribute to the understanding of MS tissue pathology by demonstrating widespread damage both in myelin and axonal components, which associate with microglial activation within the NAWM. Our study also demonstrates that the decreased WM tract integrity and microglial activation in the whole and in the segmented NAWM is associated with clinical disability and disease severity.

Our work supports the present notion that CNS damage associated with MS disease progression is associated with chronic inflammation trapped within the CNS. The diffuse, widespread inflammation likely contributes to demyelination and axonal injury as a consequence of chronic microglial activation, extensive production of reactive oxygen species, and iron accumulation. ${ }^{23}$ Inflammation is seen at all stages of the disease in chronic active MS lesions and in areas adjacent to them, i.e., also in the NAWM, with correlation between inflammation and axonal injury. ${ }^{24}$ For better understanding of the evolution of MS disease, it is important to be able to detect the diffuse neuroinflammation and associated axonal damage in vivo already before clinically evident progressive phase and before development of gross atrophy.

One weakness in our study is that the evaluated patient population was quite heterogeneous in terms of disease subtype and treatment status. However, the principal aim of the study was to explore how different imaging methods are able to capture the disseminated pathology related to MS NAWM and to test how the imaging methods correlate with each other. Our main finding was that increased microglial activation at a given time point associates with the WM tract damage in the respective brain ROI. It has been suggested based on neuropathologic studies that microglial activation contributes to neuroaxonal damage but studies addressing this question in vivo in patients with MS are scarce.

The transition of parenchymal microglia and/or infiltrating peripheral macrophages from their homeostatic (resting) state to the activated state is accompanied by the increased expression of $18-\mathrm{kDa}$ mitochondrial TSPO, therefore making $\left[\mathrm{C}^{11}\right](\mathrm{R})-\mathrm{PK} 11195$ radioligand a specific molecular marker of microglia/macrophage activation and consequently of neuroinflammation. ${ }^{25}$ The increased $\left[\mathrm{C}^{11}\right](\mathrm{R})-\mathrm{PK} 11195$ radioligand 

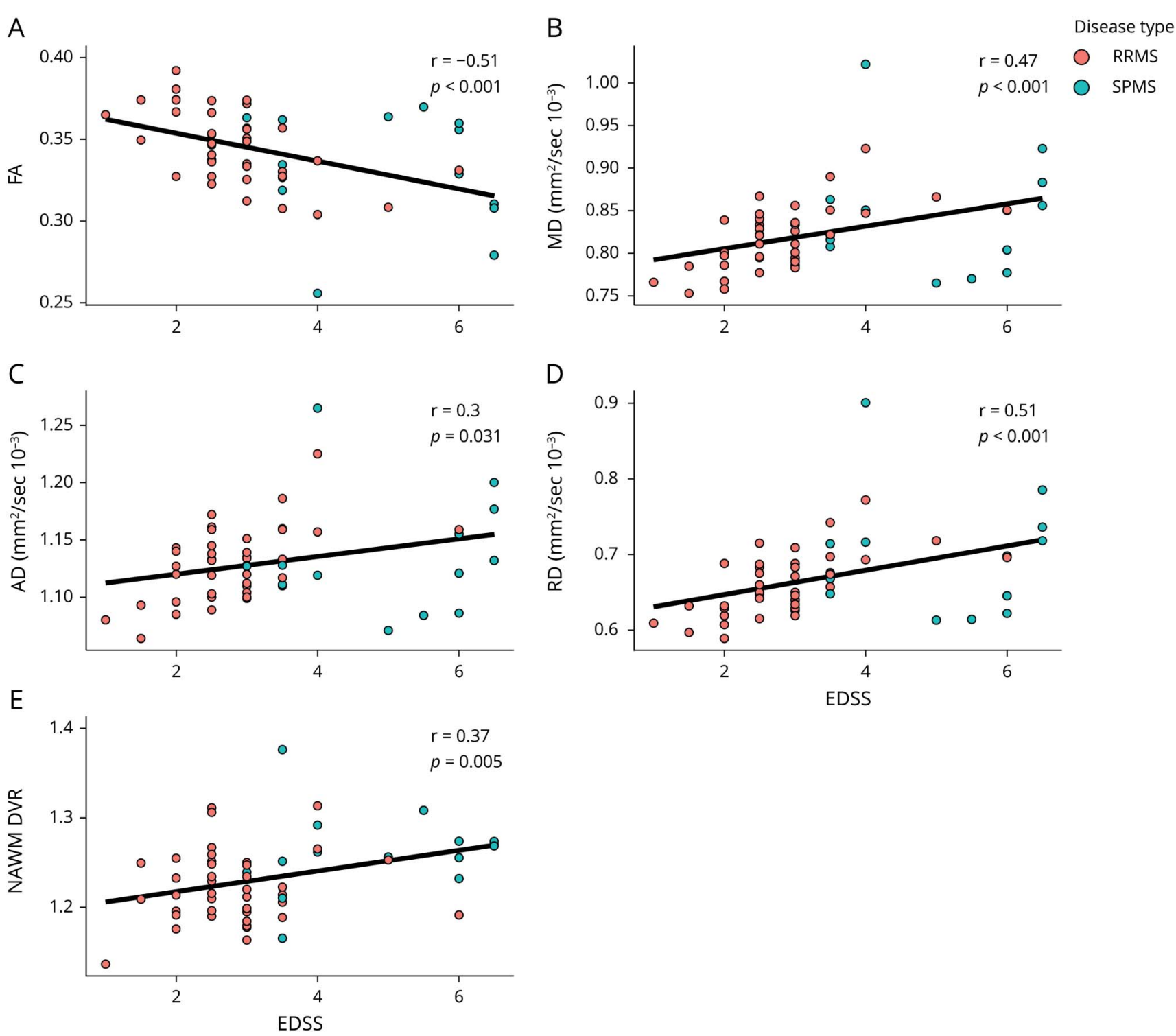

Decreased WM integrity (A-D) and increased specific binding of $\left[{ }^{11} \mathrm{C}\right](\mathrm{R})-\mathrm{PK} 11195$ measured as DVR in the global NAWM (E) is associated with clinical disability, evaluated with the EDSS score. The correlations are visualized with linear regression lines and Spearman correlation coefficient, significant at the level of $p<$ 0.05. $A D=$ axial diffusivity; $D V R=$ distribution volume ratio; $E D S S=$ Expanded Disability Status Scale; FA = fractional anisotropy; $M D=$ mean diffusivity; $N A W M=$ normal-appearing white matter; RD = radial diffusivity; RRMS = relapsing-remitting MS; SPMS = secondary progressive MS; WM = white matter.

binding may also arise from denser microglial cellularity at sites of tissue damage. ${ }^{26}$ Moreover, TSPO has been demonstrated to be upregulated also on activated astrocytes. Therefore, the detected TSPO-PET signal may originate from either cell type. ${ }^{27}$ Indeed, several animal studies ${ }^{28,29}$ have demonstrated upregulated TSPO expression in reactive astrocytes after nervous system injury, but at a significantly lower level and temporarily distinct, compared with microglia. The present understanding is that under pathologic situations, activated microglia trigger astrocyte activation, and hence both can be simultaneously detected in MS pathology. ${ }^{30}$

Several studies have demonstrated thalamic involvement in MS, with evidence of FA reduction in the thalamus ${ }^{31,32}$ that may predict disease evolution and contribute to cognitive decline and disability in MS. A common hypothesis is that focal lesions in thalamocortical projections can damage the surrounding WM, therefore leading to thalamic atrophy and neuronal loss. ${ }^{33}$ Results of the voxel-wise correlational analysis in this study demonstrated DTI pathology (reduced FA) in the thalamic radiation in 54 patients with MS, in association with increased TSPO binding as a measure of microglial activation. This is in line with the previous results on thalamic involvement in MS. ${ }^{34}$

In the voxel-wise correlation analysis, the volume of voxels with statistically significant correlation between increased TSPO binding and decreased FA was larger in the whole WM (including lesions) compared with the NAWM. It is most likely that the lower number of significant voxels in the 

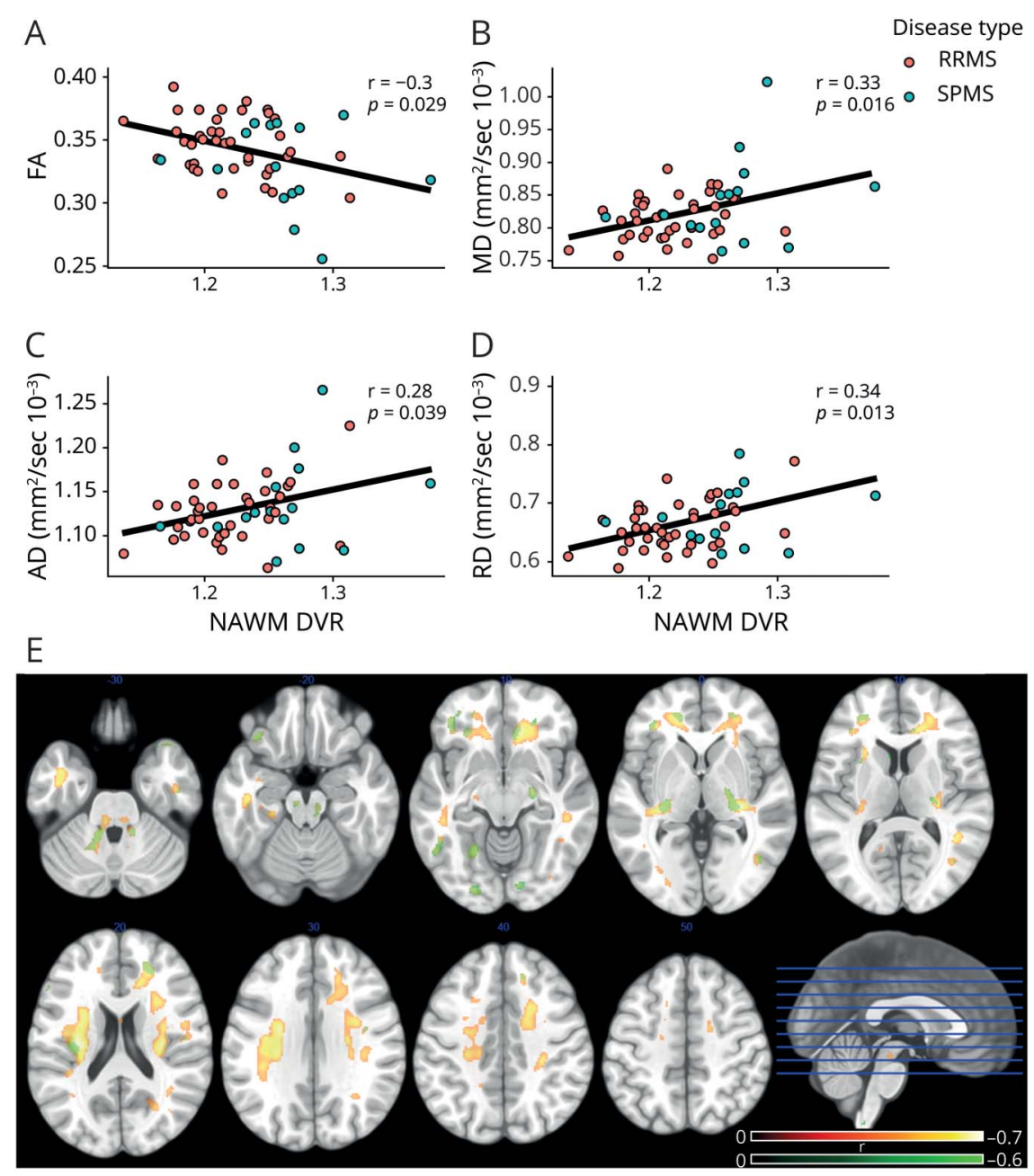

Specific binding of $\left[{ }^{11} \mathrm{C}\right](\mathrm{R})-\mathrm{PK} 11195$ measured as DVR in the NAWM correlates with FA (A) and with $M D, A D$, and $R D(B-D)$ measured within the NAWM of 55 patients with MS. The correlations are visualized with linear regression lines and Spearman correlation coefficient, significant at the level of $p<$ 0.05. Voxel-wise correlation of increased microglial activation and decreased FA in the NAWM of patients with MS is shown in (E). Statistically significant voxel-wise FA and DVR correlation coefficients in the NAWM (shown in green) and in the whole WM (shown in red-yellow) for the patients with MS ( $n=$ 54) at a group level. Correction for multiple comparisons was performed using FDR with significance level of $p<0.05$. Significant clusters were found within the superior longitudinal fasciculus, corticospinal tract, cingulate gyrus, corona radiata, and forceps minor, and also within thalamic radiation. $A D=$ axial diffusivity; DVR = distribution volume ratio; $F A=$ fractional anisotropy; $F D R=$ false discovery rate; $\mathrm{MD}=$ mean diffusivity; $\mathrm{NAWM}=$ normal-appearing white matter; $\mathrm{RD}=$ radial diffusivity; RRMS = relapsing-remitting MS; SPMS = secondary progressive MS; WM = white matter.
NAWM compared with the whole WM is due to the largely varying location of lesions between each case, thus leaving less voxels for statistical comparison with the exact same brain coordinates belonging to NAWM in all cases. Consequently, this lower number of NAWM voxels with significant correlation reduces the statistical power and results in smaller significant voxel clusters. It is plausible that both inflammatory pathology and tract-related damage is greater in areas of acute focal demyelinating lesions, but a significant correlation between increased microglial activation and reduced FA in the NAWM areas surrounding the lesions could also be demonstrated. This likely indicates the presence of chronically active lesions with accumulation of activated microglia/macrophages ${ }^{35}$ and possibly Wallerian and retrograde degeneration in the vicinity of the lesions. ${ }^{36}$ Moreover, TSPO uptake is generally lower within the chronic WM lesions, especially in SPMS than in the adjacent perilesional area and in more distant NAWM, ${ }^{10}$ but FA is also low due to demyelination. Thus, including the lesions into comparison should drive the correlation between TSPO binding and FA into the opposite direction than observed here.
In correlation analyses between WM tract integrity and disability evaluated by the EDSS score (figure 3 ), 3 patients with SPMS had relevantly preserved tract integrity (higher $\mathrm{FA}$ and lower $\mathrm{MD}, \mathrm{AD}$, and $\mathrm{RD}$ than other patients with SPMS). One of the abovementioned patients had quite heavy spinal lesion load and only very moderate brain MRI lesion load, which explains the finding of better tract integrity in the DTI findings with a high EDSS score. ${ }^{37}$

In this study we evaluate diffuse structural and molecular changes in MS using high magnetic field DTI and PET as complementary imaging modalities, performed on a large MS cohort $(n=55)$ with comparison to HCs. Combining different imaging modalities for the analysis of disease pathology in single individual patients has recently become an attractive approach in the neuroimaging field. ${ }^{38,39}$ This approach has great potential in the future for increasing our understanding of the evolution of the pathology associated with disease progression. Combination of complementary neuroimaging modalities provides a comprehensive examination of the brain structure and function in vivo. This study 
proves that the application of DTI with TSPO-PET imaging for detecting hidden neuroinflammation reveals new insights into the complexity of MS pathology.

This study provides evidence on the associations between DTI detectable abnormalities and microglial activation, measured with TSPO-PET in vivo in the NAWM of patients with MS. The study demonstrates that the combination of PET and DTI enables better appreciation of the hidden MS pathology not visible using cMRI. Future implementations of this study might be beneficial in revealing associations between fiber connectivity and enlargement of smoldering lesions with activated microglia. Combination of complementary techniques such as DTI and PET imaging may also be used as a tool for evaluation of disease progression in treatment trials of progressive MS.

\section{Acknowledgment}

All the study participants and the expert staff at Turku PET Centre are gratefully acknowledged for making this study possible. The authors are also sincerely thankful to Professor Jarmo Hietala and Dr. Heikki Laurikainen for providing the additional healthy control DTI data for the analyses and Dr. Maija Saraste for critical reading of the manuscript.

\section{Study funding}

Financial support for this study was provided by the Finnish Academy, the Sigrid Juselius Foundation, and The Finnish MS Foundation.

\section{Disclosure}

S. Bezukladova reports no disclosures. J. Tuisku was supported by the Alfred Kordelin Foundation, Instrumentarium Science Foundation, Orion Research Foundation, Paulo Foundation, Päivikki and Sakari Sohlberg Foundation, and Turku University Hospital Foundation. M. Matilainen, A. Vuorimaa, M. Nylund, and S. Smith report no disclosures. M. Sucksdorff has received personal research grants from the Finnish MS Foundation and the Finnish Medical Foundation. M. Mohammadian, V. Saunavaara, and S. Laaksonen report no disclosures. J. Rokka has received personal research grant from the Sigrid Juselius Foundation. J.O. Rinne has received research grants from the Academy of Finland, the Sigrid Juselius Foundation, and the Finnish National Neurocenter and Governmental Research Grants (VTR). E. Rissanen has received speaker honoraria from Teva, Biogen, and Roche, a consultation fee for Merck, and personal research grants from Turku University Hospital (State Research Funding) and the Finnish MS Foundation. L. Airas has received research grants from the Academy of Finland, the Sigrid Juselius Foundation, and the Finnish National Neurocenter and Governmental Research Grants (VTR), institutional research grant support from Genzyme and Merck Serono, and honoraria from Biogen, F. Hoffmann-La Roche Ltd, Genzyme, and Merck Serono. Go to Neurology.org/NN for full disclosures.

\section{Publication history}

Received by Neurology: Neuroimmunology \& Neuroinflammation October 11, 2019. Accepted in final form January 9, 2020.

\section{Appendix Authors}

\begin{tabular}{|c|c|c|c|}
\hline Name & Location & Role & Contribution \\
\hline $\begin{array}{l}\text { Svetlana } \\
\text { Bezukladova, } \\
\text { MSc }\end{array}$ & $\begin{array}{l}\text { Turku PET Centre, } \\
\text { University of Turku } \\
\text { and Turku University } \\
\text { Hospital, Finland; } \\
\text { Neuroimmunology } \\
\text { Unit, Division of } \\
\text { Neuroscience, } \\
\text { Institute of } \\
\text { Experimental } \\
\text { Neurology, IRCCS } \\
\text { San Raffaele } \\
\text { Hospital, Milan, Italy. }\end{array}$ & Author & $\begin{array}{l}\text { DTI analysis and } \\
\text { interpretation of } \\
\text { the data and } \\
\text { drafting and } \\
\text { revision of the } \\
\text { manuscript }\end{array}$ \\
\hline $\begin{array}{l}\text { Jouni Tuisku, } \\
\text { MSc }\end{array}$ & $\begin{array}{l}\text { Turku PET Centre, } \\
\text { University of Turku } \\
\text { and Turku } \\
\text { University Hospital, } \\
\text { Finland }\end{array}$ & Author & $\begin{array}{l}\text { PET data modeling } \\
\text { and analysis and } \\
\text { revision of the } \\
\text { manuscript }\end{array}$ \\
\hline $\begin{array}{l}\text { Markus } \\
\text { Matilainen, MSc, } \\
\text { PhD }\end{array}$ & $\begin{array}{l}\text { Turku PET Centre, } \\
\text { University of Turku } \\
\text { and Turku } \\
\text { University Hospital, } \\
\text { Finland }\end{array}$ & Author & $\begin{array}{l}\text { Revision of the } \\
\text { statistical analyses } \\
\text { and revision of the } \\
\text { manuscript }\end{array}$ \\
\hline $\begin{array}{l}\text { Anna Vuorimaa, } \\
\text { MD }\end{array}$ & $\begin{array}{l}\text { Turku PET Centre, } \\
\text { University of Turku } \\
\text { and Turku } \\
\text { University Hospital; } \\
\text { Division of Clinical } \\
\text { Neurosciences, } \\
\text { Turku University } \\
\text { Hospital, Finland }\end{array}$ & Author & $\begin{array}{l}\text { MR image } \\
\text { processing }\end{array}$ \\
\hline Sarah Smith, BSc & $\begin{array}{l}\text { Turku PET Centre, } \\
\text { University of Turku } \\
\text { and Turku } \\
\text { University Hospital; } \\
\text { Division of Clinical } \\
\text { Neurosciences, } \\
\text { Turku University } \\
\text { Hospital, Finland }\end{array}$ & Author & $\begin{array}{l}\text { MR image } \\
\text { processing }\end{array}$ \\
\hline $\begin{array}{l}\text { Marjo Nylund, } \\
\text { MSc }\end{array}$ & $\begin{array}{l}\text { Turku PET Centre, } \\
\text { University of Turku } \\
\text { and Turku } \\
\text { University Hospital; } \\
\text { Division of Clinical } \\
\text { Neurosciences, } \\
\text { Turku University } \\
\text { Hospital, Finland }\end{array}$ & Author & $\begin{array}{l}\text { Data collection and } \\
\text { revision of the } \\
\text { manuscript }\end{array}$ \\
\hline $\begin{array}{l}\text { Marcus } \\
\text { Sucksdorff, MD }\end{array}$ & $\begin{array}{l}\text { Turku PET Centre, } \\
\text { University of Turku } \\
\text { and Turku } \\
\text { University Hospital; } \\
\text { Division of Clinical } \\
\text { Neurosciences, } \\
\text { Turku University } \\
\text { Hospital, Finland }\end{array}$ & Author & $\begin{array}{l}\text { Data acquisition } \\
\text { (PET and MRI) and } \\
\text { MR image } \\
\text { processing }\end{array}$ \\
\hline $\begin{array}{l}\text { Mehrbod } \\
\text { Mohammadian, } \\
\text { MSc }\end{array}$ & $\begin{array}{l}\text { Turku PET Centre, } \\
\text { University of Turku } \\
\text { and Turku } \\
\text { University Hospital, } \\
\text { Finland }\end{array}$ & Author & $\begin{array}{l}\text { Supervision of DTI } \\
\text { analyses }\end{array}$ \\
\hline $\begin{array}{l}\text { Virva } \\
\text { Saunavaara, } \\
\text { PhD }\end{array}$ & $\begin{array}{l}\text { Turku PET Centre, } \\
\text { University of } \\
\text { Turku; } \\
\text { Department of } \\
\text { Medical Physics, } \\
\text { Division of Medical } \\
\text { Imaging, Turku } \\
\text { University } \\
\text { Hospital, Finland }\end{array}$ & Author & $\begin{array}{l}\text { Design of the MRI } \\
\text { and DTI protocols }\end{array}$ \\
\hline
\end{tabular}


Appendix (continued)

\begin{tabular}{llll}
\hline Name & Location & Role & Contribution \\
\hline $\begin{array}{lll}\text { Sini Laaksonen, } \\
\text { MD }\end{array}$ & $\begin{array}{l}\text { Turku PET Centre, } \\
\text { University of Turku } \\
\text { and Turku }\end{array}$ & & $\begin{array}{l}\text { Data acquisition } \\
\text { (PET and MRI) }\end{array}$ \\
& University Hospital; & \\
& Division of Clinical & \\
& Neurosciences, & \\
& Turku University & \\
& Hospital, Finland & \\
\end{tabular}

\begin{tabular}{lll}
\hline Johanna Rokka, & $\begin{array}{l}\text { Turku PET Centre, Author } \\
\text { University of Turku }\end{array}$ & $\begin{array}{l}\text { Acquisition of the } \\
\text { data } \\
\text { PhD }\end{array}$ \\
$\begin{array}{ll}\text { and Turku } & \text { University Hospital, } \\
\text { Finland } & \text { synthesis of the PET } \\
& \text { ligand) and revision } \\
& \text { of the manuscript }\end{array}$
\end{tabular}

Juha O. Rinne, Turku PET Centre, Author Concept and design
MD, PhD

$\begin{array}{lll}\text { Turku PET Centre, } & \text { Author } & \text { Concept and design } \\ \text { University of Turku } & & \text { of the } \\ \text { and Turku } & \text { experimentation; }\end{array}$
University Hospital, interpretation of Finland the data; and revision of the manuscript

\begin{tabular}{lll}
\hline $\begin{array}{l}\text { Eero Rissanen, } \\
\text { MD, PhD }\end{array}$ & Turku PET Centre, Author & $\begin{array}{l}\text { Data acquisition } \\
\text { (PET and MRI); data }\end{array}$ \\
& University of Turku & and Turku \\
University Hospital; & interpretation; \\
& Division of Clinical & planning and \\
Neurosciences, & supervision of the \\
Turku University & data analyses; and \\
Hospital, Finland & significant \\
& contribution to the \\
& writing of the \\
& manuscript
\end{tabular}

\begin{tabular}{|c|c|c|c|}
\hline $\begin{array}{l}\text { Laura Airas, MD, } \\
\text { PhD }\end{array}$ & $\begin{array}{l}\text { Turku PET Centre, } \\
\text { University of Turku } \\
\text { and Turku } \\
\text { University Hospital; } \\
\text { Division of Clinical } \\
\text { Neurosciences, } \\
\text { Turku University } \\
\text { Hospital, Finland }\end{array}$ & Author & $\begin{array}{l}\text { Group leader in } \\
\text { charge of the } \\
\text { intellectual concept } \\
\text { behind the } \\
\text { scientific work } \\
\text { presented in the } \\
\text { manuscript; } \\
\text { financially enabled } \\
\text { the } \\
\text { experimentation; } \\
\text { planning and } \\
\text { supervision of the } \\
\text { experimentation; } \\
\text { interpretation of } \\
\text { the data; and } \\
\text { significant } \\
\text { contribution to } \\
\text { the writing of the } \\
\text { manuscript }\end{array}$ \\
\hline
\end{tabular}

\section{References}

1. Thompson AJ, Baranzini SE, Geurts J, Hemmer B, Ciccarelli O. Multiple sclerosis. Lancet 2018;391:1622-1636.

2. Filippi M, Rocca MA. Conventional MRI in multiple sclerosis. J Neuroimaging 2007; 17:3-9.

3. Le Bihan D, Mangin JF, Poupon C, et al. Diffusion tensor imaging: concepts and applications. J Magn Reson Imaging 2001;13:534-546.

4. Sbardella E, Tona F, Petsas N, Pantano P. DTI measurements in multiple sclerosis: evaluation of brain damage and clinical implications. Mult Scler Int 2013;2013: $1-11$.

5. Ching ASC, Kuhnast B, Damont A, Roeda D, Tavitian B, Dollé F. Current paradigm of the 18-kDa translocator protein (TSPO) as a molecular target for PET imaging in neuroinflammation and neurodegenerative diseases. Insights Imaging 2012;3: 111-119.

6. Harel A, Sperling D, Petracca M, et al. Brain microstructural injury occurs in patients with RRMS despite "no evidence of disease activity". J Neurol Neurosurg Psychiatry 2018;89:977-982.
7. Spano B, Giulietti G, Pisani V, et al. Disruption of neurite morphology parallels MS progression. Neurol Neuroimmunol Neuroinflamm 2018;5:e502. doi: 10.1212/NXI 0000000000000502 .

8. Andersen O, Hildeman A, Longfils $\mathrm{M}$, et al. Diffusion tensor imaging in multiple sclerosis at different final outcomes. Acta Neurol Scand 2018;137:165-173.

9. Gurevich M, Waknin R, Stone E, Achiron A. Fingolimod-improved axonal and myelin integrity of white matter tracts associated with multiple sclerosis-related functional impairments. CNS Neurosci Ther 2018;24:412-419.

10. Rissanen E, Tuisku J, Vahlberg T, et al. Microglial activation, white matter tract damage, and disability in MS. Neurol Neuroimmunol Neuroinflamm 2018;5:e443. doi: 10.1212/NXI.0000000000000443.

11. Roosendaal SD, Geurts JJG, Vrenken H, et al. Regional DTI differences in multiple sclerosis patients. Neuroimage 2009;44:1397-1403.

12. Onu M, Roceanu A, Sboto-Frankenstein U, et al. Diffusion abnormality maps in demyelinating disease: correlations with clinical scores. Eur J Radiol 2012;81 e386-e391. doi: 10.1016/j.ejrad.2011.12.014.

13. Bodini B, Cercignani M, Khaleeli Z, et al. Corpus callosum damage predicts disability progression and cognitive dysfunction in primary-progressive MS after five years. Hum Brain Mapp 2013;34:1163-1172.

14. Pokryszko-Dragan A, Banaszek A, Nowakowska-Kotas M, et al. Diffusion tensor imaging findings in the multiple sclerosis patients and their relationships to various aspects of disability. J Neurol Sci 2018;391:127-133.

15. Rissanen E, Tuisku J, Rokka J, et al. In vivo detection of diffuse inflammation in secondary progressive multiple sclerosis using PET imaging and the radioligand $11 \mathrm{C}$ PK11195. J Nucl Med 2014;55:939-944.

16. Herranz E, Giannì C, Louapre C, et al. Neuroinflammatory component of gray matter pathology in multiple sclerosis. Ann Neurol 2016;80:776-790.

17. Singhal T, O'Connor K, Dubey S, et al. Gray matter microglial activation in relapsing vs progressive MS: a [F-18]PBR06-PET study. Neurol Neuroimmunol Neuroinflamm 2019;6:e587. doi: 10.1212/NXI.0000000000000587.

18. Schmidt P, Gaser C, Arsic M, et al. An automated tool for detection of FLAIRhyperintense white-matter lesions in multiple sclerosis. Neuroimage 2012;59:3774-3783.

19. Salat DH, Greve DN, Pacheco JL, et al. Regional white matter volume differences in nondemented aging and Alzheimer's disease. Neuroimage 2009;44:1247-1258.

20. Leemans A, Jones DK. The B-matrix must be rotated when correcting for subject motion in DTI data. Magn Reson Med 2009;61:1336-1349.

21. Chang LC, Jones DK, Pierpaoli C. RESTORE: robust estimation of tensors by outlier rejection. Magn Reson Med 2005;53:1088-1095.

22. Gunn RN, Lammertsma AA, Cunningham VJ. Parametric imaging of ligand-receptor binding in PET using a simplified reference region model. Neuroimage 1997;6: 279-287.

23. Lassmann H. Multiple sclerosis pathology. Cold Spring Harb Perspect Med 2018;8:1-16.

24. Frischer JM, Bramow S, Dal-Bianco A, et al. The relation between inflammation and neurodegeneration in multiple sclerosis brains. Brain 2009;132:1175-1189.

25. Liu GJ, Middleton RJ, Hatty CR, et al. The $18 \mathrm{kDa}$ translocator protein, microglia and neuroinflammation. Brain Pathol 2014;24:631-653.

26. Owen DR, Narayan N, Wells L, et al. Pro-inflammatory activation of primary microglia and macrophages increases $18 \mathrm{kDa}$ translocator protein expression in rodents but not humans. J Cereb Blood Flow Metab 2017;37:2679-2690.

27. Lavisse S, Guillermier M, Herard A-S, et al. Reactive astrocytes overexpress TSPO and are detected by TSPO positron emission tomography imaging. J Neurosci 2012;32: 10809-10818.

28. Maeda J, Higuchi M, Inaji M, et al. Phase-dependent roles of reactive microglia and astrocytes in nervous system injury as delineated by imaging of peripheral benzodiazepine receptor. Brain Res 2007;1157:100-111.

29. Chen $\mathrm{M}-\mathrm{K}$, Guilarte TR. Imaging the peripheral benzodiazepine receptor response in central nervous system demyelination and remyelination. Toxicol Sci 2006;91: 532-539.

30. Peterson TC, Buckwalter MS, Panicker N, et al. Neurotoxic reactive astrocytes are induced by activated microglia. Nature 2017;541:481-487.

31. Mesaros S, Rocca MA, Pagani E, et al. Thalamic damage predicts the evolution of primary-progressive multiple sclerosis at 5 years. Am J Neuroradiol 2011;32:1016-1020.

32. Deppe M, Krämer J, Tenberge JG, et al. Early silent microstructural degeneration and atrophy of the thalamocortical network in multiple sclerosis. Hum Brain Mapp 2016; 37:1866-1879.

33. Minagar A, Barnett MH, Benedict RHB, et al. The thalamus and multiple sclerosis: modern views on pathologic, imaging, and clinical aspects. Neurology 2013;80: 210-219.

34. Vercellino $\mathrm{M}$, Masera $\mathrm{S}$, Lorenzatti $\mathrm{M}$, et al. Demyelination, inflammation, and neurodegeneration in multiple sclerosis deep gray matter. J Neuropathol Exp Neurol 2009;68:489-502.

35. Zrzavy T, Hametner S, Wimmer I, Butovsky O, Weiner HL, Lassmann H. Loss of "homeostatic" microglia and patterns of their activation in active multiple sclerosis. Brain 2017;140:1900-1913.

36. Singh $\mathrm{S}$, Dallenga $\mathrm{T}$, Winkler A, et al. Relationship of acute axonal damage, Wallerian degeneration, and clinical disability in multiple sclerosis. J Neuroinflammation 2017;14:1-15.

37. Cohen $\mathrm{AB}$, Neema $\mathrm{M}$, Arora $\mathrm{A}$, et al. The relationships among MRI-defined spina cord involvement, brain involvement, and disability in multiple sclerosis. J Neuroimaging 2012;22:122-128.

38. Teipel S, Drzezga A, Grothe MJ, et al. Multimodal imaging in Alzheimer's disease: validity and usefulness for early detection. Lancet Neurol 2015;14:1037-1053.

39. Uludağ K, Roebroeck A. General overview on the merits of multimodal neuroimaging data fusion. Neuroimage 2014;102:3-10. 


\title{
Neurology \\ Neuroimmunology \& Neuroinflammation
}

\author{
Insights into disseminated MS brain pathology with multimodal diffusion tensor and \\ PET imaging \\ Svetlana Bezukladova, Jouni Tuisku, Markus Matilainen, et al. \\ Neurol Neuroimmunol Neuroinflamm 2020;7; \\ DOI 10.1212/NXI.0000000000000691
}

This information is current as of March 2, 2020

\begin{abstract}
Updated Information \&
Services

including high resolution figures, can be found at:

http://nn.neurology.org/content/7/3/e691.full.html

References

This article cites 39 articles, 7 of which you can access for free at: http://nn.neurology.org/content/7/3/e691.full.html\#\#ref-list-1

Citations

This article has been cited by 1 HighWire-hosted articles:

http://nn.neurology.org/content/7/3/e691.full.html\#\#otherarticles

Subspecialty Collections

This article, along with others on similar topics, appears in the following collection(s):

DWI

http://nn.neurology.org//cgi/collection/dwi

Multiple sclerosis

http://nn.neurology.org//cgi/collection/multiple_sclerosis

PET

http://nn.neurology.org//cgi/collection/pet

Permissions \& Licensing

Information about reproducing this article in parts (figures,tables) or in its entirety can be found online at:

http://nn.neurology.org/misc/about.xhtml\#permissions

Reprints

Information about ordering reprints can be found online:

http://nn.neurology.org/misc/addir.xhtml\#reprintsus

Neurol Neuroimmunol Neuroinflamm is an official journal of the American Academy of Neurology.

Published since April 2014, it is an open-access, online-only, continuous publication journal. Copyright

Copyright $\odot 2020$ The Author(s). Published by Wolters Kluwer Health, Inc. on behalf of the American

Academy of Neurology.. All rights reserved. Online ISSN: 2332-7812.
\end{abstract}

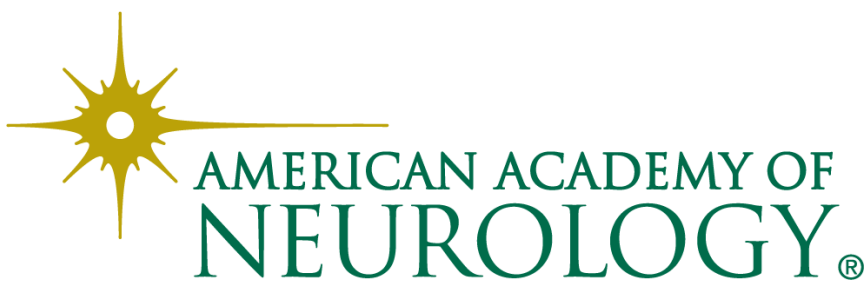

